\title{
New opportunity for dissemination of regional research results in the Asia-Pacific region
}

\author{
Sarwar Jahan ${ }^{1,2}$
}

Published online: 15 March 2017

(C) The Japan Section of the Regional Science Association International 2017

The publication of Asia-Pacific Journal of Regional Science (APJRS) comes as great news for the students, teachers, researchers, and professionals interested in publishing papers based on theoretical and empirical research on regional science in Asia-Pacific region. This is particularly important for countries in the region undergoing rapid transformation in various socio-economic fields. As a rapidly developing country of the region, Bangladesh faces numerous challenges resulting from economic and demographic shifts. Regional researchers and spatial analysts of the country have found quite significant variations in the distribution of benefits of development across regions of the country. Policy makers of Bangladesh are also concerned about the growing disparities in rural-urban and regional per capita incomes and how to address this problem in a prudent manner.

Another important challenge for the country is the rapid growth of urban population, especially in big cities. Uncontrolled growth of Dhaka, the primate city of the country, generates negative externalities through congestion and pollution. Continuous flow of people towards the big cities poses serious problems for promotion of more dispersed urban development.

Global warming and climate change also come up as a major challenge for the country's continued development. Though Bangladesh's contribution to global greenhouse gas emissions is one of the lowest, its unfavourable geophysical conditions, high density of population, and widespread poverty make it extremely vulnerable to climate change. Climate change-related impacts such as drought, flooding and extreme rainfall, cyclone, tornadoes, and sea-level rise have become

Sarwar Jahan

sjahan50@gmail.com

1 Urban and Regional Planning, Bangladesh University of Engineering and Technology, Dhaka, Bangladesh

2 Bangladesh Regional Science Association, Dhaka, Bangladesh 
major concerns for the country because of the adverse impacts, these may have on development activities.

These and various other issues and challenges are providing the regional scientists of Bangladesh with fertile grounds for research. There are ample opportunities for research on such issues as the relationship between urbanization and regional development, effects of national policies on regional and sub-regional growth, spatial variations and driving forces in economic performance of various sectors and industries, policies for growth and dispersion of urban systems, analyses of socio-economic, physical, and environmental aspects relevant for disaster risk reduction and climate change adaptation, policies for addressing the problems of lagging regions and so on. Numerous other problems and issues of inter-disciplinary nature have important implications for local and regional development and, therefore, need in-depth study and analysis. Regional scientists, planners, economists, and researchers of various other disciplines in Bangladesh will find the APJRS as a very useful media for dissemination of their research results. This will not only provide avenues for further research in spatial aspects of development but also will help the policy makers in formulating policies and strategies to address pressing regional problems and other emerging issues. I am quite confident about the success of the Journal, and wish the editors and publishers very best in their current and future endeavours. 